\title{
Análise do descarte ambientalmente correto da produção do queijo coalho em fabriquetas do Sertão Sergipano
}

O queijo de coalho vem ocupando um lugar relevante na alimentação humana devido ao seu alto valor nutritivo, contudo, é responsável pelo fomento de uma grande quantidade de rejeito ou efluentes líquidos decorrentes da transformação do leite em queijo. O principal efluente proveniente desta transformação é o soro de queijo, este que é considerado um dos grandes poluentes da indústria de laticínios e fabriquetas de pequeno, médio e grande porte, rico em gorduras, lactoses e proteínas. Atualmente é muito pouco aproveitado para fins alimentícios e todo volume desperdiçado é enviado para nutrição de suínos, ou direcionados a mananciais de água ou solo, gerando problemas ambientais como alta demanda bioquímica de oxigênio. Neste sentido é de extrema relevância buscar alternativas para o descarte ambientalmente correto e tratamentos adequados do soro de queijo. O presente estudo objetivou investigar com as fabriquetas do Alto Sertão Sergipano destinam os seus resíduos ou efluentes provenientes da produção de queijo de coalho. A pesquisa é caracterizada como descritiva, realizada sob a forma de estudo de caso, com base de análise quantitativa, além da observação direta nas propriedades. Aplicou-se uma amostragem não probabilística por conveniência, utilizando o questionário estruturado como instrumento e aplicado na amostra de 18 proprietários de fabriquetas de queijo de coalho. No que se refere ao tratamento dos dados, estes foram compactados e exportados para o software Microsoft Office Excel, sendo analisados priorizando os aspectos sócio- ambientais. Os resultados evidenciaram que 16 proprietários responderam que os efluentes decorrentes do processo produtivo do queijo são constituídos de soro e 2 é constituído de soro e água de lavagem, que todos os proprietários responderam que o destino dado aos resíduos líquidos decorrentes do processo produtivo é voltado para alimentação dos suínos, todos os proprietários responderam que não realizam nenhum tratamento aos rejeitos gerados pelas mesmas, que $83 \%$ da amostra consideram que os rejeitos provenientes da produção não causam impactam em seu cotidiano e $17 \%$ são indiferentes aos seus efeitos. Identificou-se também que 10 proprietários responderam que desconhecem sobre os danos causados ao meio ambiente que o soro pode provocar, 5 conhecem pouco e 3 conhecem. Finalmente, cabe ressaltar a necessidade de demonstrar e discutir os impactos ambientes causados pelos rejeitos da produção do queijo coalho no Sertão Sergipano.

Palavras-chave: Destinação de Efluentes; Meio Ambiente; Produção de Queijo Coalho.

\section{Analysis of environmentally correct disposal of type cheese coalho production "homemade" in the droughts of Sergipe}

\begin{abstract}
The curd cheese has occupied an important place in human nutrition due to its high nutritional value, however, it is responsible for the development of a large amount of waste or liquid waste arising from the processing of milk into cheese. The main effluent from this transformation is the cheese whey, this is considered one of the dairy industry of polluting and sweatshops of small, medium and large, rich in fats and proteins lactoses. It is currently very little exploited for food purposes and all wasted volume is sent to pig nutrition, or directed to water sources or soil, creating environmental problems such as high biochemical oxygen demand. In this sense it is extremely important to seek alternatives to environmentally correct disposal and proper cheese whey treatments. This study aimed to investigate the sweatshops of the High Wilderness Sergipe intended their waste or effluent from curd cheese production. The research is characterized as descriptive, held in the form of case study, based on quantitative analysis, as well as direct observation in the properties. Applied non-probability sampling for convenience, using the structured questionnaire as a tool and applied to the sample of 18 owners of curd cheese homemade. With regard to the processing of data, they were compressed and exported to Microsoft Office Excel software, and analyzed prioritizing the socioenvironmental aspects. The results showed that 16 owners responded that the effluents from the production of the cheese making process consist of serum and 2 consists of whey and wash water, which all owners responded that the destination of the liquid waste from the production process is facing feeding pigs, all owners said they do not perform any treatment of waste generated by them, that $83 \%$ of the sample consider that the waste from the production cause no impact on their daily lives and $17 \%$ are indifferent to its effects. It also identified that 10 owners said they are unaware of the damage caused to the environment that may cause serum, 5 and 3 know little know. Finally, it points out the need to demonstrate and discuss the environment impact caused by waste from the production of cheese curds in the droughts of Sergipe.
\end{abstract}

Keywords: Disposal of Effluents; Environment; Type Coalho Cheese Production

Topic: Engenharia Sanitária

Reviewed anonymously in the process of blind peer.

Érica Emília Almeida Fraga

Universidade Federal de Sergipe, Brasil

http://lattes.cnpq.br/6628225424707263

fragaerica@hotmail.com

Simone Maria da Silva Rodrigues

Universidade Federal de Sergipe, Brasil

http://lattes.cnpq.br/3277512872924366

smsr.direito@hotmail.com

Cleiton Rodrigues de Vasconcelos (iD) Universidade Federal de Sergipe, Brasil http://lattes.cnpq.br/5572250848026213 http://orcid.org/0000-0003-3318-2982 cleitongv@yahoo.com.br

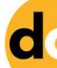

DOI: 10.6008/SPC2179-6858.2016.002.0010
Received: 05/01/2016

Approved: 10/04/2016

\author{
José Ricardo de Santana \\ Universidade Federal de Sergipe, Brasil \\ http://lattes.cnpq.br/0326719214777541 \\ josericardo.santana@fapitec.se.gov.br \\ Mário Jorge Campos dos Santos \\ Universidade Federal de Sergipe, Brasil \\ http://lattes.cnpq.br/5451087590848842 \\ mjkampos@gmail.com \\ Daniel Pereira da Silva \\ Universidade Federal de Sergipe, Brasil \\ http://lattes.cnpq.br/2804708148095897 \\ silvadp@hotmail.com
}

\section{Referencing this:}

FRAGA, E. E. A.; RODRIGUES, S. M. S.; VASCONCELOS, C. R.; SANTANA, J. R.; SANTOS, M. J. C.; SILVA, D. P.. Análise do descarte ambientalmente correto da produção do queijo coalho em fabriquetas do Sertão Sergipano. Revista Ibero-Americana de Ciências Ambientais, v.7, n.2, p.126-135, 2016. DOI: http://doi.org/10.6008/SPC2179-6858.2016.002.0010 


\section{INTRODUÇÃO}

A relação entre meio ambiente e crescimento econômico vem ganhando destaque ao longo tempo, seja pelos efeitos do crescimento econômico no meio ambiente, os impactos tecnológicos e a difusão dada pela mídia diante dessas mudanças.

As discussões ambientais no mundo ressaltam a importância e a necessidade de se buscar um desenvolvimento socialmente justo e ecologicamente sustentável, capaz de transformar o caos atual entre o binômio desenvolvimento e meio ambiente.

Considerando-se o desenvolvimento sustentável como o desenvolvimento que trata de forma entrelaçada e interdependente as variáveis econômicas, social e ambiental, objetiva a garantia de uma melhor qualidade de vida para as atuais e futuras gerações. A execução do desenvolvimento sustentável perpassa por um processo de discussão e envolvimento da sociedade como um todo, uma vez que impacta em mudanças no modo de ser, pensar e agir dos agentes sociais, numa perspectiva de conscientizar a efetiva participação da comunidade local na utilização, conservação e monitoramento de seus recursos naturais.

No Brasil, o setor de laticínios vem crescendo exponencialmente e está no foco das discussões atuais no que tange o meio ambiente. O grande cerne dessa problemática diz respeito a sua produção, que tem ocasionado cada vez mais um maior número de resíduos ou efluentes. Dentre os inúmeros produtos do setor, o queijo é o maior responsável pela geração de soro, este que é um subproduto da fabricação de queijo e que apresenta uma elevada concentração de matéria orgânica incorporada. Assim, uma destinação incorreta do soro de queijo pode conduzir graves problemas ambientais como a poluição das águas, geração de odores desagradáveis, bem como o comprometimento da estrutura físico-química do solo.

O município de Nossa Senhora da Glória apresenta uma organização singular do setor leiteiro por congregar vários agentes da cadeia produtiva, com maneiras muito diferenciadas no processamento do leite (industrial, artesanal, familiar ou caseiro). A produção de queijo de coalho no Alto Sertão Sergipano é de extrema importância para a economia e desenvolvimento da região e encontra-se bastante difundida, com perspectivas de crescimento das empresas de laticínios.

A produção de queijo é responsável por uma grande quantidade de rejeito ou efluentes líquidos, decorrentes do processamento do leite. Dentre estes efluentes, encontra-se o soro, que é um dos poluentes líquidos que mais corroboram para a alta carga poluidora das indústrias de laticínios e que acarreta graves problemas ambientais associados ao seu alto teor de matéria orgânica.

Neste sentido, é de extrema importância que as fabriquetas de queijo de coalho do município de Nossa Senhora da Glória estejam efetivamente conscientes tanto do destino ecologicamente correto do soro quanto do seu tratamento.

Quando realizado o tratamento adequado, o soro de queijo pode ser aproveitado para a confecção de pães, extratos de leveduras, concentrados protéicos, sorvetes, iogurtes, ricota, assim como pode ser utilizado como elemento emulsionante de água em produtos cárneos em função de suas proteínas presentes. 
Neste contexto, o presente trabalho teve como objetivo investigar com as fabriquetas do Alto Sertão Sergipano destinam os seus resíduos ou efluentes provenientes da produção de queijo de coalho.

\section{REVISÃO TEÓRICA}

\section{A Importância do Desenvolvimento Sustentável}

O mundo vem se defrontando com inúmeros problemas característicos da sociedade pós-industrial, dentre eles a dificuldade em aliar o crescimento econômico com a proteção ao meio ambiente. Para se alcançar um desenvolvimento sustentável, é preciso levar em conta as dimensões sociais, econômicas, ecológicas, espaciais e culturais - numa visão multidisciplinar com o intuito de analisar as variáveis e todo o imenso desafio de atender às necessidades materiais e imateriais da sociedade de forma equitativa.

De acordo com Bursztyn (1993), pode se pensar em desenvolvimento considerando-se as seguintes dimensões da sustentabilidade:

Sustentabilidade ecológica - constitui a base física do processo de crescimento e tem como objetivos a conservação e o uso racional do estoque de recursos naturais incorporados às atividades produtivas. Assegura a compatibilidade do desenvolvimento com a manutenção dos processos ecológicos essenciais, bem como com a biodiversidade e os recursos hídricos. Sustentabilidade social e cultural - assegura que o desenvolvimento aumenta o controle das pessoas sobre suas vidas, é comparável com a cultura e os valores morais do povo por ele afetado e que mantém e fortalece a identidade da comunidade. A meta é construir uma sociedade com maior equidade na distribuição de renda, de modo a reduzir o abismo entre pobres e ricos, procurando preservar sua identidade. Sustentabilidade econômica assegura que o desenvolvimento é economicamente eficaz e que os recursos São geridos de modo a poder suportar as gerações futuras. A eficiência econômica deve ser avaliada em termos macrossociais, e não somente considerar a rentabilidade empresarial de caráter microeconômico. Sustentabilidade espacial - deve ser dirigida para a obtenção de uma configuração rural-urbana mais equilibrada e uma melhor distribuição territorial dos assentamentos humanos e das atividades econômicas.

Ainda tratando das dimensões acima citadas, Bursztyn (1993), contudo, levanta a questão que todos são favoráveis ao desenvolvimento sustentável, mas pouco se sabe a respeito de como incorporar a sua ideologia ao processo de planejamento do desenvolvimento nacional, regional ou local.

Corroborando com o pensamento de Bursztyn, Cavalcanti (1995) justifica que esta aparente inabilidade de como incorporar o conceito de sustentabilidade e a visível falta de interesse pode ser justificada levando-se em considerações três fatores:

A concepção de que uma nova ideia demanda um certo tempo para ser incorporada; a interpretação errônea, principalmente por grande parte da política econômica, de que o assunto não diz respeito à comunidade em geral, mas deve ser tratado exclusivamente por ambientalistas, e; a crise econômica das décadas de 80 e início das de 90, que tornou ainda mais difícil a incorporação de novas dimensões no processo de planejamento.

As discussões que geram em torno do desenvolvimento sustentável expõem estratégias conflitantes que respondem a olhares e interesses distintos. O olhar economicista privilegia o livre mercado como modo para internalizar as externalidades ambientais e para valorizar a natureza, recodificando a ordem da vida e da cultura em termos de capital natural e humano.

A transição para a sustentabilidade, fundada numa racionalidade ambiental, implica pensar a complexidade no processo de produção. Isto leva a pensar a produção como um sistema complexo, fundado 
nos efeitos sinergéticos dos processos que mobilizam a produtividade ecológica, a inovação tecnológica, as significações culturais e a energia social (Leff, 2000).

Pensar em sustentabilidade no Brasil requer uma quebra de paradigmas, tendo em vista a ampla diversidade de cenários e interesses. No entanto, se faz necessário estabelecer o direito à educação, a formação ambiental ligado aos princípios da sustentabilidade, à capacitação, que permita a cada indivíduo e cada sociedade produzir e apossar-se de saberes e fazeres, para participar na gestão de seus métodos de produção, decidir sobre suas condições de existência e eleger sua qualidade de vida.

\section{Produção do Queijo de Coalho}

O queijo vem ocupando um lugar relevante na alimentação humana devido ao seu alto valor nutritivo, sendo considerado, por muitos, um alimento completo. Sua composição varia de acordo com o tipo e a matéria-prima utilizada, tendo como seus principais componentes a água, alto valor de cálcio, lipídios, lactose e vitaminas lipossolúveis, bem como outros nutrientes.

Na concepção de Monteiro (2011) o queijo é "o produto obtido a partir do leite coalhado, separado do soro e amadurecido durante tempo variável. Pode ser definido como um concentrado proteico-gorduroso resultante da coagulação do leite, seguido da dessora do coágulo que causa o decréscimo na umidade".

Em se tratando especificamente do queijo coalho, o Regulamento Técnico de Identidade e Qualidade, constante da Instrução Normativa $\mathrm{n}^{\circ}$ 30, de 26/06/01, do Ministério da Agricultura, Pecuária e Abastecimento, considera que este é "queijo que se obtém por coagulação do leite por meio do coalho ou outras enzimas coagulantes apropriadas, complementada ou não pela ação de bactérias lácteas selecionadas, e comercializado normalmente com até 10 (dez) dias de fabricação".

Para a produção de todo e qualquer alimento é essencial a adoção de critérios que visam o controle de qualidade do produto. $O$ processo produtivo de queijo coalho também deverá atender ao sistema de APPCC (Análise de Perigos e Pontos Críticos de Controle), com o intuito de prevenir a ocorrência de potenciais problemas, assim como na adoção de Boas Práticas de Fabricação (BPF) (SILVA, 2000).

De acordo com Menezes (2001), foi a partir da década de 1990 que proliferaram o número de fabriquetas de queijo no Estado de Sergipe, que geraram forte concorrência na aquisição da matéria-prima, assim como na venda dos derivados do leite, não sendo absorvida toda a produção do estado de Sergipe, ultrapassando fronteiras e atingindo outros estados nordestinos e em certos períodos o centro-sul. Essas unidades de produção, em algumas áreas de Sergipe, apresentam-se como única alternativa de mercado para os pequenos, médios e grandes produtores.

\section{Rejeitos Gerados na Produção de Queijo Coalho e o Meio Ambiente}

Os processos, operações e ocorrências em função do beneficiamento do leite geram significativa quantidade de efluentes líquidos ou sólidos e que podem comprometer sistematicamente o meio ambiente. $\mathrm{Na}$ indústria de laticínios, a quantidade e a carga de poluentes das águas residuárias (efluentes) variam muito, 
depende diretamente dos tipos de produtos e da quantidade de água utilizada, bem como da tecnologia e do controle de qualidade despendido no processo produtivo (Braile, 1991).

A produção de queijo é responsável pelo fomento de uma grande quantidade de rejeito ou efluentes líquidos e sua produção é semelhante as demais unidades de processamento da indústria de laticínio, acrescido de coágulos de leite e seu pH é mais baixo do que do processamento de leite e de creme e, além do soro gerado nessa transformação (MACHADO et. al., 2002).

Para Amiot (1991):

O soro de leite é um líquido claro de cor amarelada que se separa da coalhada durante a fabricação do queijo. O soro é a fase aquosa, opaca e de coloração verde amarelada, obtido durante a produção do queijo ou precipitação da caseína, resultante da coagulação do leite por ácido ou enzimas proteolíticas. Sua composição varia substancialmente dependendo da variedade de queijo ou caseína produzidos. O soro é uma fonte econômica de proteínas que oferece uma série de benefícios funcionais em inúmeras aplicações alimentícias (solubilidade, viscosidade, emulsificação, gelificação e outras).

Corroborando com Amiot, Farro (2003) diz que aproximadamente $20 \%$ do total das proteínas do soro apresentam funcionalidades biológicas elevadas quando em comparação com outras fontes proteicas, além de integrar um teor de aminoácidos correspondente a $60 \%$ do valor proteico total do soro.

Já de acordo com Gonzalez (1996), " o soro de leite apresenta em média 93\% de água, 5,0\% de lactose, $0,5 \%$ de gordura, $0,8 \%$ de proteínas solúveis, $0,7 \%$ de sais minerais, além de ácido láctico, compostos nitrogenados não proteicos e vitaminas".

No entanto, é preciso ter em mente que o soro de leite traz também outras características que, tendo seu destino incorreto, acarretará em danos ao meio ambiente. Nesse sentido Petrus (2000) assevera que "o soro apresenta uma carga orgânica cerca de cem vezes maior que a do esgoto doméstico, responsável por causar um grande impacto ambiental”.

Por esse motivo, há uma preocupação recorrente em gerar aplicabilidade ao soro de queijo em novos alimentos, visto que, no território brasileiro, cerca de 50\% do soro não é aproveitado, gerando desperdícios nutricional, financeiros e impactos ambientais relevantes, já que é um resíduo com alto teor orgânico (MAGALHÃES et al., 2011).

\section{Tratamento do Rejeito Líquido}

O tratamento convencional de efluentes ou rejeitos da transformação do leite em derivados, envolve o uso de tratamento primário para remoção de sólidos, óleos e gorduras presentes no efluente, tratamento secundário para remoção de matéria orgânica e nutriente e, em alguns ínfimos casos, tratamento terciário como polimento.

Segundo Dallas (1999), a quantidade de soro gerado no processo de fabricação de queijo é função do tipo de queijo produzido e das técnicas de fabricação empregadas e em média $80 \%$ a $90 \%$ do volume total do leite utilizado é separado como soro. O grande transtorno no tratamento do soro de leite, enquanto despejo industrial, discorre Braile (1991), é a grande concentração em matéria orgânica e a deficiência em 
nitrogênio dificultando de maneira relevante a estabilização do soro de leite por meio de métodos convencionais de tratamento biológico.

Atualmente, dentre as técnicas de tratamento de rejeitos, encontra-se o tratamento do soro por ultrafiltração (UF), sendo bastante explorado, sobretudo, nos países desenvolvidos, o qual é responsável por uma redução na Demanda Biológica de Oxigênio (DBO) da ordem de 20\%. Da UF do soro de queijo se obtém concentrados proteicos, o retentado, solução rica em proteínas; e, o permeado, solução rica em lactose. De elevado valor nutritivo, com propriedades funcionais de considerável interesse na indústria láctea e de alimentos, o retentado torna-se um substituto potencial de ingredientes como o leite em pó, albumina de ovo e soja (Viotto, 1997)

Ainda de acordo com Viotto (1997), uma das grandes vantagens do uso de UF, na produção de queijo é um aumento no rendimento do produto devido à incorporação das proteínas do soro, normalmente perdidas no soro de queijo, e não obstante a redução da DBO.

Conforme salienta Bortoleto (1997), na indústria de alimentos a utilização dos resíduos pode revelarse uma atividade com exímios resultados econômicos, pois além da venda dos subprodutos ou novas matérias-primas geradas no processo, haverá uma melhoria significativa na preservação ambiental, e, indubitavelmente, haverá uma redução considerável nos custos que circundam o processo de tratamento dos efluentes.

\section{METODOLOGIA}

O Alto Sertão Sergipano é constituído pelos municípios de Nossa Senhora da Glória, Gararu, Monte Alegre de Sergipe, Porto da Folha, Poço Redondo e Canindé do São Francisco. Este território foi eleito por ter como atividade social e econômica a produção de leite e seus subprodutos. Porém, a aplicação dos questionários ficou restrita ao município de Nossa Senhora da Glória. Tal município localiza-se na região noroeste do estado de Sergipe e ocupa uma área de 756,490 Km² , com uma população de 32.497 habitantes (IBGE, 2014).

A pesquisa utilizou procedimentos de caráter quantitativo e qualitativo. No que diz respeito aos fins a pesquisa intitulou-se descritiva, pois teve como objetivo expor as características de determinada população ou fenômeno. Quanto ao meio caracterizou-se como bibliográfica e de estudo de caso.

Para a seleção da amostra na pesquisa, utilizou-se o método de amostragem não probabilística por conveniência, diante do interesse dos entrevistados em participar da pesquisa. O método utilizado foi o estudo de caso, tendo como instrumento de coleta de dado o questionário contendo perguntas abertas e fechadas sobre os aspectos socioambientais das fabriquetas, além da observação direta nas propriedades.

Foram contemplados os produtores de queijo de coalho do Município de Nossa Senhora da Glória pelo fato deste ter forte presença da pecuária do leite como sua principal atividade econômica, assim como um número elevado de fabriquetas de queijo coalho. 0 tamanho da amostra da pesquisa se constituiu de 18 fabriquetas do município pesquisado. 


\section{RESULTADOS E DISCUSSÃO}

O território do Alto Sertão exerce um papel de extrema importância social e econômica para Sergipe, pois se trata de uma região produtora de leite e seus subprodutos. Dentre os sete municípios que fazem parte do Alto Sertão Sergipano, Nossa Senhora da Glória destaca-se em nível de produção e de processamento de leite.

Considerado como o centro dessa bacia leiteira, este município exerce uma significativa influência regional. Essa liderança ultrapassa os limites geográficos dos municípios circunvizinhos e outras microrregiões (MENEZES, 2001).

Nossa Senhora da Glória localiza-se na região noroeste do estado de Sergipe e ocupa uma área de $756,490 \mathrm{Km}^{2}$, com uma população de 32.497 habitantes, onde se encontra a maior concentração de população economicamente ativa e o setor agropecuário é o principal empregador do território (IBGE, 2014).

Neste estudo, foram aplicados no período de janeiro de 2016, 18 (dezoito) questionários a proprietários de fabriquetas de queijo coalho em funcionamento no município de Nossa Senhora da Glória. Foram elaboradas cinco questões direcionadas aos aspectos sócio- ambientais: resíduos decorrentes do processo produtivo do queijo de coalho, destino dado aos resíduos líquidos decorrentes do processo produtivo, tipo de tratamento no descarte dos resíduos líquidos da produção, os rejeitos descartados pela fábrica influenciam no cotidiano e conhecimento a respeito dos danos causados ao meio ambiente que o soro pode provocar.

Quanto a questão dos resíduos decorrentes do processo produtivo do queijo de coalho, 16 proprietários responderam que os efluentes são constituídos de soro e 2 é constituído de soro e água de lavagem, como demonstrado na Figura 1.

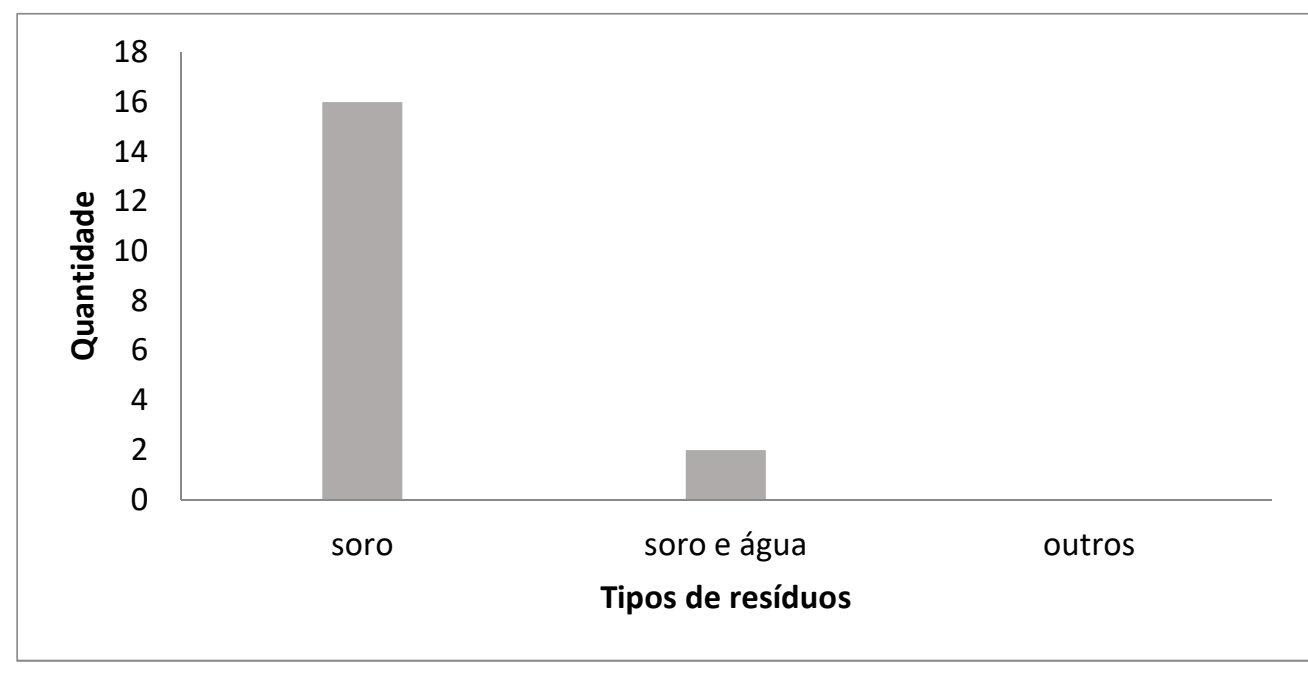

Fonte: elaborado pelos autores

No que trata da questão do destino dado aos resíduos líquidos decorrentes do processo produtivo, todos os proprietários responderam que o destino é voltado para alimentação dos suínos. A falta de alternativas eficazes e economicamente viáveis para o uso do soro conduz os proprietários a considerarem a
Figura 1 - Resíduos decorrentes do processo produtivo do queijo de coalho 
suinocultura como a sua segunda maior fonte de renda, sobretudo, nos períodos de seca, cuja produção do leite cai e, por conseguinte, a produção do queijo coalho.

Com relação a questão acima, resultados similares foram encontrados por Menezes (2001), com $82,4 \%$ das queijarias do município de Nossa Senhora da Glória associadas à suinocultura. Esta atividade é uma importante alternativa de renda para estes produtores, tornando-se viável a partir da introdução do soro lácteo resultante do processamento do queijo, utilizado como subproduto na complementação alimentar dos animais, além de contribuir para a minimização dos impactos ambientais, uma vez que esse subproduto não é lançado no meio ambiente

Quanto ao destino dado aos resíduos líquidos decorrentes do processo produtivo, todos os proprietários responderam que não realizam nenhum tratamento aos rejeitos gerados pelas mesmas. Porém, concordam em investir no processo produtivo no intuito de minimizar possíveis problemas ambientais pertinentes ao mesmo, desde que sejam dadas as condições econômicas necessárias.

Questionados sobre se o descarte dos resíduos pelas fabriquetas influenciam no seu cotidiano, $83 \%$ da amostra consideram que os rejeitos provenientes da produção não causam impactam em seu cotidiano e 17\% são indiferentes aos seus efeitos, como demonstrado na Figura 2. Ressalta-se aqui que tal resultado é perfeitamente previsível, tendo em vista que todo o soro proveniente da produção de queijo é utilizado na alimentação de suínos.

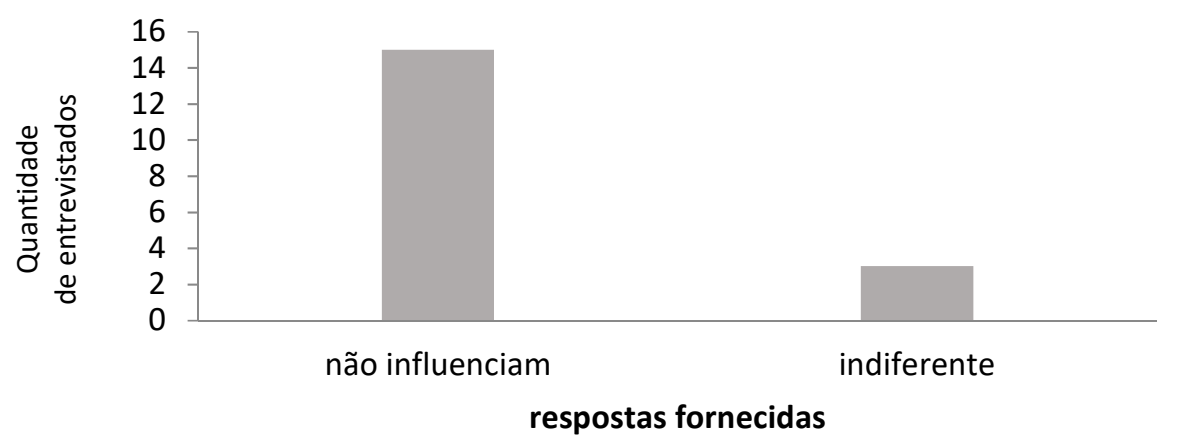

Figura 2 - Influência dos rejeitos da produção de queijo no cotidiano Fonte: elaborado pelos autores

No que diz respeito ao conhecimento dos danos causados ao meio ambiente que o soro pode provocar, 10 proprietários responderam que desconhecem o assunto, 5 conhecem pouco e 3 conhecem, como mostra a Figura 3. O que leva a presumir que tal desconhecimento esteja diretamente relacionado ao baixo nível de escolaridade dos indivíduos consultados, representando um possível entrave do conhecimento sobre as consequências e implicações causadas pela atividade produtiva ao meio ambiente. 


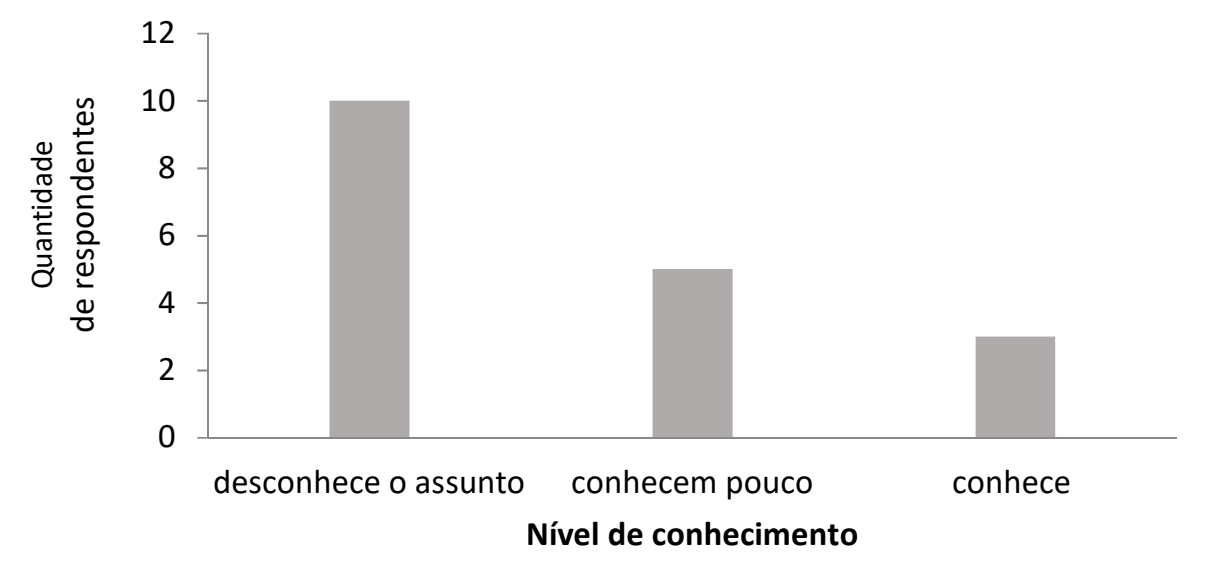

Figura 3 - Conhecimento acerca dos danos causados pelo soro

Fonte: elaborado pelos autores

Conforme os resultados apresentados, verificou-se que a produção do queijo coalho no Alto Sertão Sergipano, é extremamente importante para economia local, conforme apontado por Menezes (2001). Porém, no tocante ao aspecto ambiental da produção do queijo, constatou-se que o sistema é complexo, tendo em vista, que grande parte dos produtores desconhecem os danos causados pelos resíduos na cadeia produtiva do produto. Situação esta apontada por Petrus (2000) que assevera que " o soro apresenta uma carga orgânica cerca de cem vezes maior que a do esgoto doméstico, responsável por causar um grande impacto ambiental".

Destacou-se também que os resíduos líquidos decorrentes do processo produtivo, é voltado para alimentação dos suínos, ou seja, a maior vantagem do negócio está na criação de suínos, alimentados com os rejeitos provenientes desta manufatura láctea.

\section{CONCLUSÕES}

A maior bacia leiteira do Estado de Sergipe encontra-se no território do Alto Sertão Sergipano, tendo destaque, em termos de produção de queijo coalho, o município de Nossa Senhora da Glória.

A preocupação com o meio ambiente tem gerado reflexão e amadurecimento da cadeia produtiva do leite e seus derivados, e como consequência na destinação adequada de efluentes e resíduos, que deve buscar a garantia do equilíbrio ambiental a fim de proteger o meio ambiente de possíveis impactos gerados pelos laticínios.

Neste contexto, detectou-se que a produção do queijo coalho no Alto Sertão Sergipano é fator primordial para economia da região. Percebeu-se que os proprietários das fabriquetas sabem que é preciso cuidar do meio ambiente, porém a maioria desconhece os prejuízos causados pelos efluentes líquidos gerados na produção. 
Portanto, verificou-se que é necessário investir em educação ambiental e conscientização junto aos produtores, além de traçar estratégias de negócios com intuito de angariar incentivos financeiros para atividade.

\section{REFERÊNCIAS}

AMIOT, J.. Ciencia y tecnologia de la leche: principios y aplicaciones. Zaragoza: Acribia, 1991.

BORTOLETO, M. L. A.. Leite: Realidade e Perspectivas. Governo do Estado de São Paulo, Secretaria de Agricultura e Abastecimento. Coleção Cadeias de Produção da Agricultura. São Paulo, 1997.

BRAILE, P. M.. Tratamento de Despejos de Laticínios. In: Manual de Tratamento de Águas Residuárias Industriais. CETESB. São Paulo, FESB. São Paulo, 1991.

BRASIL. Ministério da Agricultura, Pecuária e Abastecimento Instrução Normativa no 30, de $\mathbf{2 6}$ de junho de 2001. Aprova os regulamentos técnicos de identidade e qualidade de manteiga da terra ou manteiga de garrafa; queijo de coalho e queijo de manteiga. Brasília, 16 de jul. 2001.

\section{BURSZTYN, M.. Para Pensar o Desenvolvimento}

Sustentável. São Paulo: Editora Brasiliense, 1993.

CAVALCANTI, C.. Desenvolvimento e natureza: estudos para uma sociedade sustentável. São Paulo: Cortez; Recife: Fundação Joaquim Nabuco, 1995.

DALLAS, P.. O Uso de Derivados de Soro em Aplicações de Produtos de Consumo. Leite e derivados, v.8, n.46, p.48-50, 1999.

FARRO, P. C. A.. Ultrafiltração do Soro de Queijo Minas Frescal Pró-tratado e micro filtrado: Efeitos da vazão volumétrica e da pressão transmembrana no fluxo de permeado. Dissertação (Mestrado em Engenharia de Alimentos) - Universidade Estadual de Campinas, São Paulo, 2003.

GONZALÉZ, S. M. I.. The Biotechenological Utilization of Cheese Whey a Review. Bioresource Technology, v.57, n.11, p.1-11, 1996.

LEFF, E.. Ecologia, capital e cultura: racionalidade ambiental, democracia participativa e desenvolvimento sustentável. Blumenau: EdFURB, 2000.
LIMA, M. H. P.. Elaboração de queijo de coalho a partir de leite pasteurizado e inoculado com $S$. thermophillus e $L$. bulgaricus. Dissertação (Mestrado em Tecnologia de Alimentos) - Universidade Federal do Ceará, Fortaleza, 1996.

MACHADO, R. M. G; FREIRE, V. H.; SILVA, P. C.; FIGUERÊDO, D. V.; FERREIRA, P. E.. Controle ambiental nas pequenas e médias indústrias de laticínios. Projeto Minas Ambiente, Belo Horizonte, 2002.

MAGALHÃES, K. T.; DRAGONE, G.; PEREIRA, G. V. M.; OLIVEIRA, J. M.; DOMINGUES, L.; TEIXEIRA, J. A.; SILVA, L. B. A.; SCHWAN, R. F.. Comparative study of the biochemical changes and volatile compound formations during the production of novel whey-based kefir beverages and traditional milk kefir. Food Chemistry, v.126, p.249-253, 2011.

MENEZES, S. S. M.. As fabriquetas de queijo: uma estratégia de reprodução camponesa no Município de Itabí/SE. Dissertação (Mestrado em Geografia Agrária) - Universidade Federal de Sergipe, 2001.

MONTEIRO, A. A.; PIRES, A. C. S.; ARAÚJO, E. A.. Tecnologia de Produção de Derivados do Leite. Viçosa: UFV. 2011.

PELEGRINI, D. H. G.; CARRASQUEIRA, R. L.. Aproveitamento do soro do leite no enriquecimento nutricional de bebidas. Brazylian Journal Food, v.62, n.6, p.1004, 2008.

PONSANO, E. H. G.; CASTRO-GOMEZ, R. J. H.. Fermentação de soro de queijo por Kluyveromyces fragilis como uma alternativa para a redução de sua capacidade poluidor. Ciência e Tecnologia de Alimentos, v.15, n.2, p.170-173, 1995.

SILVA, J. A. E.. Manual de Controle Higiênico-Sanitário em Alimentos. São Paulo: Varela, 2000.

VIOTTO, L. A.. Fracionamento das proteínas do leite utilizando membranas cerâmicas de micro e ultrafiltração. Tese (Doutorado em Engenharia de Alimentos) Universidade Estadual de Campinas, São Paulo,1997. 